\title{
Service Customization: Optimizing Value Creation and Capture by Designing the Customer Journey
}

\author{
Jürg Meierhofer \\ School of Engineering \\ Zurich University of Applied Sciences \\ $\mathrm{CH} 8401$ Winterthur, Switzerland \\ juerg.meierhofer@zhaw.ch
}

\author{
Christoph Heitz \\ School of Engineering \\ Zurich University of Applied Sciences \\ $\mathrm{CH} 8401$ Winterthur, Switzerland \\ christoph.heitz@zhaw.ch
}

\begin{abstract}
Service customization is a central issue in sociotechnical service ecosystems, enabled and fueled by new datadriven approaches, and with the goal of increasing value creation for the customer, and value capture for the provider. In this paper, we address the question of how to design service customization within the provider-customer interaction. We propose a novel quantitative approach for modeling the relation between customization level at the various steps of the customer journey on the one hand, and its effect on the value created for customer and provider on the other hand. Combining this model with approaches from multi-objective optimization, optimum levels of customization from both the customer and the provider perspective can be determined. Thus, the proposed model allows the identification of service designs which are optimized in terms of their value creation and value capture.
\end{abstract}

Index Terms - smart services, customer journey, customization, interaction modelling, value creation, value capture

\section{INTRODUCTION}

\section{A. The Shift to Value Creation by Services}

The service sector is continuously growing and makes up a substantial part of employment and the gross domestic product [1]. The transition from products to services follows a change from the concept of "Goods-Dominant Logic" (G-D Logic) to "Service-Dominant Logic" (S-D Logic). By this transition, both manufactuerers and service firms become more servicecentric. In S-D Logic, service is considered the fundamental purpose of economic exchange [2]. The concept of manufacturing companies as service providers has emerged [3]. The focus of the value creation is moved from the provider to the co-creation in the customer interaction, resulting in increased attention to the provider-customer interaction (Fig. 1).

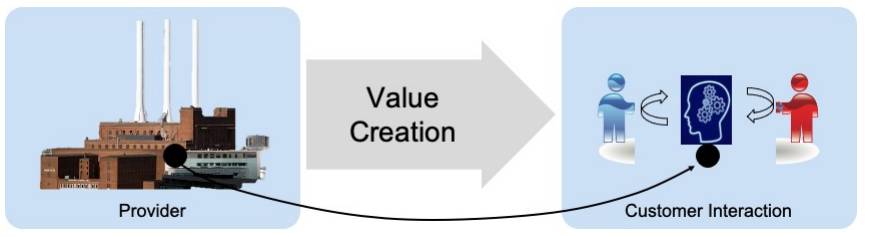

Fig. 1. Moving the value creation from the factory to the customer interaction.

The shift to services is driven by saturated markets and high competitive intensity [4] as well as the customer demand for the values and benefits provided by services [5]. In particular, there is an evolution of the customer to demand and pay for customized services. Therefore, the transition from goods to services and the addition of services to products is considered essential [6]. The omnipresence of information and communications technology is a major driving factor for the development of the service economy [7].

For the providers, the service business has considerable value capture potential by creating additional revenue and increasing customer loyalty. They extend their product business by selling services with higher margins [8]. Additional benefits come from more stable cash flows due to generating continuous revenue from the installed base, which is less susceptible to economic fluctuations than new sales [5]. Providers capture value from services in the form of higher performance, lower operational risks, and reduced fixed costs.

\section{B. Value Creation by the Interaction among Humans and Digital Agents}

The concepts introduced with the S-D Logic provide a theoretical and conceptual framework for the design of value creation in service ecosystems - networks of actors that generate value for each other by service interactions [9], [10]. Values arise in the interaction between human individuals or the longer the more - between human individuals and machines in the form of digital actors [11]. Examples are: assistance by (chat-) bots in a private or business context, assistance for mechanics when repairing a machine, training of work steps, assistance for users in an online shop. Focussing on the dyad between two actors, there is a bi-directional value flow between these. For each direction, there is a provider and a receiver, with the provider delivering value to the receiver - a process called value creation - and retaining some proportion of the value created for its own benefit - called value capture [12].

The concepts for the design of service ecosystems aim at individualized, people-centred value creation (e.g. [13], [14]). With the advent of digital technology, service systems have evolved towards hybrid human-machine systems. There is the new premise that thanks to data science, digital actors will increasingly act autonomously and become user-individualised [15], [16], e.g. develop adaptively in value creation, respond 


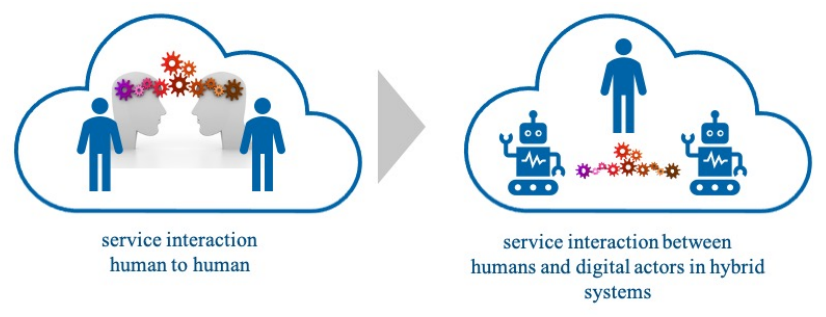

Fig. 2. The shift of value creation to interactions between humans and digital actors.

to their (human) counterparts and allow them more degrees of freedom in their decisions [11].

\section{Value Creation and Value Capture}

The interaction among humans and technical agents is conceptually discussed in the literature about socio-technical systems (e.g., [17]-[19]). Those human and technical actors interplay in service ecosystems and create and capture value [12] in the sphere of their service interaction [20]. This system of value creation can be brought down to the dyadic interaction between a service provider and a service beneficiary, with the provider supporting the beneficiary overcome the challenges to get its jobs done. Models for quantifying and measuring the service value in the process or customer journey are described in, e.g., [21]-[23]. [23] provides a modelling approach for value creation in a service encounter as a function of the joint effort between the customer and the provider with [24] introducing the expectation gap between the obtained and expected customer benefit to the models. [25] models the discrete steps of a customer dialogue as a vector whose elements stand for costs for different dialog dimensions in the steps of the dialogue. Despite many publications in this field, there is a lack of quantitative models for value creation and capture in service interactions along the customer journey. In particular, it is not clear how the increased customization potential in hybrid ecosystems as postulated by [11], [15], [16] quantitatively impacts the value creation and value capture. On the one hand, we would expect that investing in customization generally increases the value created for the customer. But it creates additional cost for the provider, thus reducing value capture. However, this might not be the case in all situations. On the other hand, customisation efforts can be done at different steps of the customer journey, and the value effects might depend strongly on the step. Hence, it is not clear, at which step which level of customisation effort should be chosen.

Addressing this gap, the research question of this paper is: How does customization along the customer journey quantitatively impact value creation for the customer and value capture for the provider and how can these values be optimized? For answering this question, we suggest a novel approach by quantitatively modelling service value creation along the customer journey, explicitly taking into account the aspect of customization. In section II, the model is described. In section III, we apply it to an exemplary case study and show how it can be used to optimize both value creation and value capture.

\section{MODEL FOR VALUE CREATION AND CAPTURE}

Our modelling approach describes the relation between degree of customization on the one hand, and its impact on the customer and the provider value on the other hand. The model is based on the customer journey, as it is here where the interaction happens. Analogously to [25], we model the customer journey by $\mathrm{n}$ steps or phases. Typical customer actions based on [26] are shown in Fig. 3. The customer first gets, or is made, aware of the service (e.g., hits over a promotion), then decides to use the service by joining it (e.g., by downloading an app or by signing a contract), followed by a use phase (step) and finally coming to a decision point to renew - eventually upgrade - or leave the service including recommendation actions to other users. It needs to be stated that according to the "zoom-in / zoom-out" principle, the time axis can be scaled arbitrarily. E.g., the four steps can extend over the whole period of the customer lifecycle with an individual step extending over a longer, continuous time period such as, e.g., several years of operations of a capital equipment in the use phase. Or - zoomed in to the use phase - just over a single problem case starting with the user getting aware of a problem, calling a customer support desk, getting the problem solved and closing the case with a satisfaction survey. Although the customer journey shown in Fig. 3 has four steps, the model is generic in its nature and can be adapted to different types of journeys with different numbers of steps.

From the perspective of the customer, perception of customization is governed by the customer's expectation for individualized service, modelled by the vector variable $\vec{C}=$ $(C(1), C(2), \ldots, C(3))$. If the service is not sufficiently individualized, the customer has to exert an effort to adapt (vector variable $\vec{C}$ in the model). For the provider, the degree of customization leads to a corresponding effort to customize the service, expressed by the vector variable $\vec{P}$ (section II-A). Based on this, we then derive a model for the impact of the customization on the value created (variable $V_{c}$ in the model) and captured (variable $V_{p}$ in the model) (section II-B).

\section{A. Model for the Customer and Provider Effort along the Customer Journey}

The lower part of Fig. 3 visualizes the role of customization in the customer journey by showing the individual customer expectations for customization and the customization efforts by the providers per step of the journey. In each step, the customer has a given degree of expected customization, with a completely standardized case as reference. This is modelled by the variable $C(i)(1 \leq i \leq n, n=4$ in the example), with $C(i)$ being normalised to the interval $[0 \ldots 1]$, which makes up the vector $\vec{C}$ of length $n . C(i)=0$ means no customer expectation for customization, $C(i)=1$ maximum expectation. For example, the customer may have little customization expectation in the "get aware" step, being content 
with mass advertisement. The same customer may have higher customization expectation in subsequent steps, e.g., expecting personal support for the installation of the service in the step "join". The customer's customization needs are mirrored by the provider's effort to adapt its service to these expectations - indicated by the variable $P(i)$ with $1 \leq i \leq n$, with $P(i)$ being normalised to the interval $[0 \ldots 1]$, or the vector $\vec{P}$, respectively. Here, $P(i)=0$ means the provider invests no effort for customization, $P(i)=1$ denotes maximum effort.

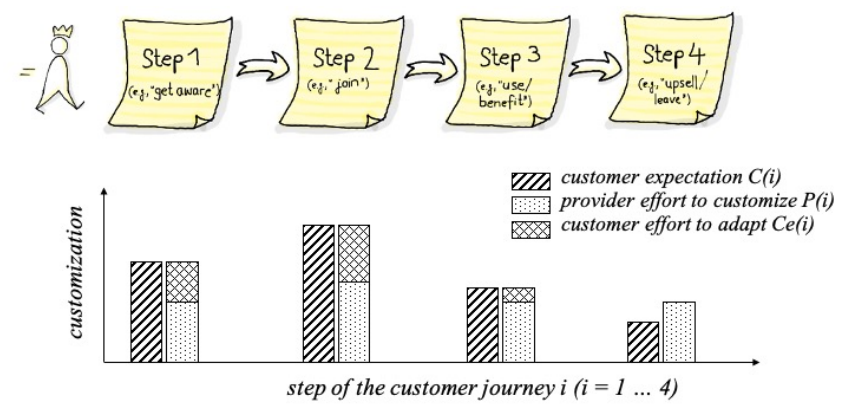

Fig. 3. Customer journey with typical customer actions (example with four steps).

If the customer expects a higher customization in step $i$ than the provider is able to provide $(C(i)>P(i))$, the customer need is not sufficiently met by the provider. This expectation gap, which is also reported in the literature in the context of service quality gap models (e.g., [24], [27]), results in an additional effort of the customer when using the service. We denote this non-fulfilment gap by the customization effort $C_{e}(i)$ (with the corresponding vector $\vec{C}_{e}$ ). If the customer expectation is lower than the provider effort, there is no additional customer investment, but the provider wastes its effort. Therefore,

$$
C_{e}(i)=\left\{\begin{array}{rll}
C(i)-P(i) & : & C(i)>P(i) \\
0 & : & \text { else }
\end{array}\right.
$$

\section{B. Quantitative Model for the Value Creation and Value} Capture

According to [28], the value created for the customer is given by the customer benefit after discounting of the customer's service costs. We assume that value is created throughout the customer journey, and we model the cumulative value created for the customer, $V_{c}$, by a walk through the steps as

$$
V_{c}=V_{\text {Cbase }}-P_{r}-C_{E \text { ffortCustomer }}
$$

with $V_{C b a s e}$ denoting the value created for the customer by the service itself without any adaption efforts along the customer journey. $P_{r}$ denotes the price paid by the customer and $C_{E \text { ffortCustomer }}$ the total cost of the customer effort for adapting to the provider's limited capability to customize. $C_{E f f o r t C u s t o m e r}$ is a function of the total customer effort over all steps of the customer journey, $\vec{C}_{e}$ (elements as in Eq. 1), i.e.:

$$
C_{E \text { ffortCustomer }}=f_{\text {CustomerCost }}\left(\vec{C}_{e}\right)
$$

The function $f_{\text {CustomerCost }}(\cdot)$ accounts for different weights of the customer effort in different steps of the customer journey and for possible non-linear effects. For example, the customer may assign little cost to investing a small effort but then get overly exhausted if the customization gets too far apart of the expectation.

The value captured by the provider can be formulated in a similar way. Similar to [29] and Eq. 2, we model the cumulative value captured by a firm from a customer's walk through the journey as the net profit, i.e., the revenue after deducting the service delivery cost. Thus, $V_{p}-$ the value captured for the provider - is described as

$$
V_{p}=V_{\text {Pbase }}+P_{r}-C_{E \text { ffort Provider }}
$$

where again $P_{r}$ stands for the price paid by the customer, the primary source of value capture. $V_{\text {Pbase }}$ accounts for potential additional elements of value capture such as, e.g., value in the form of customer insight stemming from customer cocreation [30]. The total customization efforts are described by $C_{E \text { ffortProvider. Analogous to Eq. 3, } C_{E f f o r t P r o v i d e r} \text { is a }}$ function of the total provider effort for customization over all steps of the customer journey, $\vec{P}$, i.e.:

$$
C_{\text {EffortProvider }}=f_{\text {ProviderCost }}(\vec{P})
$$

Again, the transformation function $f_{\text {ProviderCost }}(\cdot)$ of Eq. 5 reflects that fact that that the customization costs may be step-dependent and may depend non-linearly on the effort. E.g., customizing the step "join" (e.g., registration for a new app) of the customer journey may be expensive because the customer is not yet known sufficiently by the provider, whereas there are more efficient ways to customize the use phase.

\section{MODEL APPLICATION}

The model introduced in section II is now applied to investigate the value creation and capture for a specific customer-provider scenario. This scenario is exemplary, for the sole purpose of illustrating the application of the model. Our interest is focused on the question whether there is an optimum degree of customization for the provider in terms of value capture for itself $\left(V_{p}\right)$ and value creation for the customer $\left(V_{c}\right)$. The example shows a provider who initially assumes that customization efforts have the biggest effect if they are mainly invested in the "use" phase and in the step "leave/upsell" of the customer journey (operating point A in the example shown in Fig. 6). Thus, customization is used for increasing the customer lifetime value by creating a strong customer loyalty during the extended "use" phase and for winning back customers wanting to churn. However, as we will show, the application of the model suggests that focussing the customization effort on other steps of the customer journey might create considerably higher customer value at the same provider cost (operating point $\mathrm{B}$ in Fig. 6), or considerably 
lower provider costs for the same customer value (operating point $\mathrm{C}$ in Fig. 6).

\section{A. Customer Model}

For applying the model for the customer value $V_{c}$ according to Eq. 1, 2, and 3, we assume a customer journey with four steps, and a customer with the following expectation for customization: $\vec{C}=[0.75,1,0.5,0.2]$, with the values indicating the customer expectation for customization on a range $[0 \ldots 1]$. This means that the customer expects quite high personalization in the step "get aware", maximum personalization in the step "join", medium in the step "use", and very little in the step "leave/upsell". We chose these values for reflecting a use case of an individualized consumer shopping app:

- For getting attracted by this service offer, a relatively highly personalized approach in the "get aware" phase is necessary, since many alternative apps are on the market.

- Furthermore, since the app should deliver shopping recommendations based on individual preferences to be specified by the customer during the setup, the "join" phase needs substantial investment of the customers. Hence, they have a very high expectation for personalization in this phase.

- During the "use" phase, the customer gets acquainted with the service and therefore is able to adapt to the service. Hence, we assume a medium expectation for personalization here.

- When leaving the service at the end of the lifecycle (phase "leave/upsell"), the customer does not care about a personalized handling, therefore, has low expectation.

For the sake of simplicity, we assume the customer cost function $f_{\text {CustomerCost }}\left(\vec{C}_{e}\right)$ of Eq. 3 to be linear $\left(C_{E f f o r t C u s t o m e r}=\sum \alpha_{i} \cdot C_{e}(i)\right)$ with $\alpha_{i}=0.25$, for all $i$ and the values $P_{r}=1$ and $V_{\text {Cbase }}=2$.

\section{B. Provider Model}

The provider value VP is modelled according to Eq. 4 and 5 setting $V_{\text {Pbase }}=0.5$. For shedding light on the value capture process of the provider, we model the provider's cost of customization, $f_{\text {ProviderCost }}(\vec{P})$, for the different steps of the customer journey as shown in Fig. 4. As a simplifying assumption, we assume a similar order of magnitude in costs for the different steps.

- Except for the customer journey phase "use", we broadly assume that the provider's cost for offering customization monotonically increases with its customization effort.

- The customization costs for the step "get aware" grow faster than linear, assuming that a moderate level of customization can be achieved at relatively low costs, e.g., using ad words, whereas high personalization requires highly advanced measures.

- We assume that the costs for customizing the step "join" grow fast already at low degrees of customization because at this early stage the customer is largely unknown to the provider, but a saturation at higher personalization because of assumed economies of scale once the customization infrastructure is in place.

- A special case is modelled for the "use" phase: Customization in this phase may be realized by collecting data on the usage patterns of the customer and adapting the service accordingly. This requires investments in analytics and big data infrastructure. If this is implemented at a large scale, it can be deployed and applied to the mass of customers and use cases, finally resulting in decreased costs per individual walk through the customer journey.

- For the "upsell/leave" phase, we assume linearly growing costs since customizing this step largely means implementing individual disengagement measures and customer retention measures based on personal interactions, e.g., by contact centre staff.

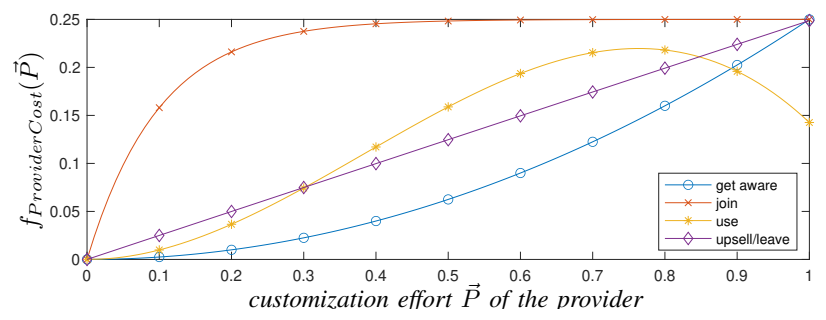

Fig. 4. Provider cost function $f_{\text {ProviderCost }}(\vec{P}$ (for the different steps of the customer journey).

\section{Evaluation the Optimum Customization Degree}

Given the customer and provider model of section III-A and III-B above, the value creation $V_{c}$ and value capture $V_{p}$ are now computed for different configurations of provider customization effort $\vec{P}$.

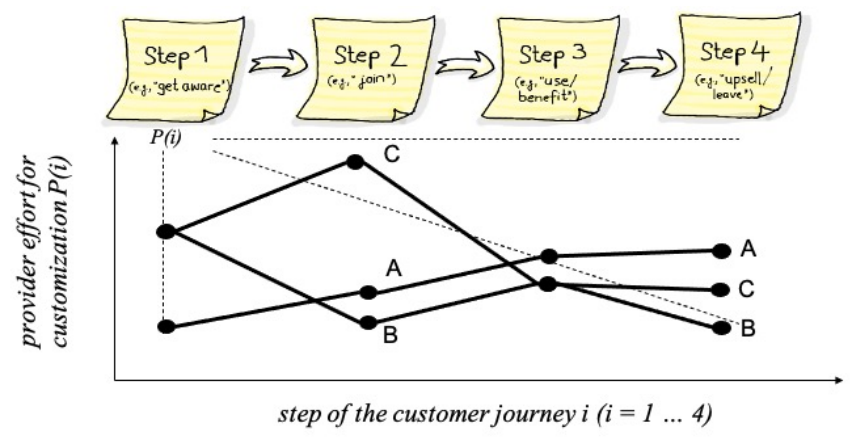

Fig. 5. Examples for the provider effort for customization $\vec{P}$ during the four steps of the customer journey.

The standard procedure for evaluating the optimum degree of customization with respect to value creation would be to combine $V_{p}$ and $V_{c}$ into a common objective variable by a weighted sum and finding the customization degree for the steps of the customer journey that maximizes this sum. However, in the case of the service ecosystem situation at hand here, $V_{p}$ and $V_{c}$ are not directly comparable because of the completely different value contexts of the customer 
and the provider which result in different, not comparable, valuation schemes. An alternative approach for this situation is given by the concept of the multi-objective optimization (e.g., [31]). In this approach, all possible combinations of the independent variables (i.e., the customization degrees in the different steps of the customer journey, $\vec{P}$ ), impacting the two target variables $V_{p}$ and $V_{c}$, are considered. The two target variables are represented in a scatter plot as shown in Fig. 6.

For the plot shown in Fig. 6, the provider effort for customization $\vec{P}$ was sampled in 16 equidistant steps for each step of the customer journey (Fig. 5). This results in the $16^{4}$ possibilities of the provider effort vector as exemplarily indicated by the three trajectories A, B, or C in Fig. 5. These example trajectories correspond to the operating points later discussed in TABLE $I$ and shown in Fig. 6. Each of the $16^{4}$ trajectories and corresponding value constellation $\left(V_{p}, V_{c}\right)$ represent a point in the scatter plot of Fig. 6, indicating the different possible service solutions. The upper right limit of the solution region defines the so-called Pareto frontier (see [31]).

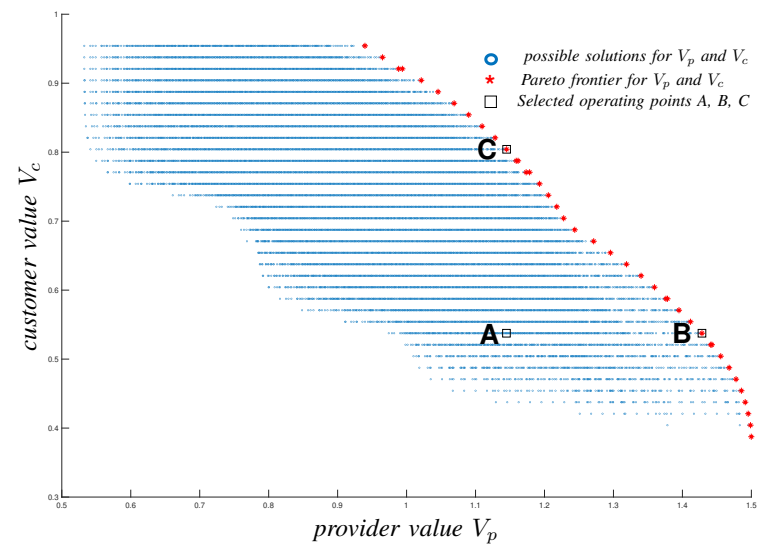

Fig. 6. Pareto frontier for $V_{p}$ and $V_{c}$ in the given example case.

As can be seen in Fig. 6, the vast majority of possible solutions (i.e., those below the Pareto frontier) are such that they can be improved both in provider value and in customer value, and thus do not represent useful solutions. What remains are the solutions on the Pareto frontier, where improving one value component (e.g., $V_{p}$ ) can only be achieved by worsening the other one (i.e., $V_{c}$ ). Hence, the Pareto frontier represents the optimal sub-set of possible customization configurations that the provider should select from. So, from a service design perspective, the possible solutions can be reduced to the solutions on the Pareto frontier. Within this sub-set, however, a trade-off between value capture and value creation for the customer has to be accepted. For the selected operating points $\mathrm{A}, \mathrm{B}$, and $\mathrm{C}$ in Fig. 6, TABLE I displays the values for the provider effort for customization $P(i)$ and the resulting value captured by the provider $\left(V_{p}\right)$ and created for the customer $\left(V_{c}\right)$.
TABLE I

CUSTOMIZATION AND VALUE CREATION AND CAPTURE FOR SELECTED OPERATING POINTS

\begin{tabular}{|l|l|l|l|l|l|l|}
\hline & \multicolumn{3}{|l|}{$\begin{array}{l}\text { Customization } \begin{array}{l}\text { effort } \tilde{\mathbf{P}} \\
\text { provider per } \\
\text { journey } \\
\text { (relative to max. }\end{array} \text { effort) } \\
\text { step }\end{array}$} & & \\
\hline $\begin{array}{l}\text { Operating } \\
\text { point }\end{array}$ & $\begin{array}{l}\text { Get } \\
\text { aware } \\
\mathbf{P}(\mathbf{1})\end{array}$ & $\begin{array}{l}\text { Join } \\
\mathbf{P}(\mathbf{2})\end{array}$ & $\begin{array}{l}\text { Use } \\
\mathbf{P}(\mathbf{3})\end{array}$ & $\begin{array}{l}\text { Upsell } \\
\text { /leave } \\
\mathbf{P}(\mathbf{4})\end{array}$ & $\mathbf{V}_{\mathbf{p}}$ & $\mathbf{V}_{\mathbf{c}}$ \\
\hline $\mathrm{A}$ & $6 \%$ & $13 \%$ & $44 \%$ & $50 \%$ & 1.15 & 0.54 \\
\hline $\mathrm{B}$ & $50 \%$ & $6 \%$ & $19 \%$ & $6 \%$ & 1.43 & 0.54 \\
\hline $\mathrm{C}$ & $50 \%$ & $94 \%$ & $19 \%$ & $19 \%$ & 1.15 & 0.80 \\
\hline
\end{tabular}

This makes evident that operating point $\mathrm{A}$, which was assumed to be the initial choice of the provider, is far from being optimal. Changing the design to solution $\mathrm{C}$ allows the provider to create roughly $50 \%$ more customer value while keeping its own value captured constant, i.e., at the same cost. On the other hand, the provider could move to operating point $\mathrm{B}$, which would allow to increase its own value by roughly $25 \%$ while keeping the value created for the customer constant. These are both remarkable improvements compared to the initial assumption of operating point A.

\section{Discussion of the Model Application}

The presented example shows that the vast majority of possible solutions are far from the Pareto front and can be improved at no extra cost simply by re-allocating customization efforts within the customer journey. The fact that the Pareto Frontier consists of only a small number of solutions is found in most applications of multi-criteria optimization problems. Without a quantitative model of the resulting effect of value creation and value capture, it is not possible to determine whether or not a specific service design lies on the Pareto frontier. Thus, the knowledge of the Pareto frontier and the service configurations associated with the solutions on the Pareto frontier enables a service provider to design the customization effort along the customer journey in a conscious way in order to realize an optimum constellation of customer and provider value. In particular, the service provider is prevented from sticking with a suboptimal constellation below the Pareto frontier, in which one of the values $V_{p}$ or $V_{c}$ can be improved without negatively impacting the other one.

However, the service provider still has the open design question where on the Pareto frontier to select its operating point. It could, for instance, opt for a higher customer value creation while capturing lower value for itself (point $\mathrm{C}$ in Fig. 6). This might be a viable strategy in, for instance, markets characterized by commoditization effects and fierce competition and thus a high negotiation power of the customer. The reduced captured value for a single service execution would then be compensated by increased sales numbers. On the other hand, a constellation as indicated by point B creates lower value for the customer but captures more value for the 
provider. Depending on the competitive situation, this might be a better option than $\mathrm{C}$.

It is important to note that these observations, considerations, and resulting improvement suggestions are only possible with a quantitative model that links the design variables (here the customization) with value creation and value capture. Since customer interaction, including human-machine interaction, is at the heart of every service, the customer journey is the natural object for establishing this link. With the presented model, we provide such a model and close a gap in the research literature on service design and value creation.

\section{OPEN QUESTIONS AND RESEARCH OUTLOOK}

Our approach establishes a valuable instrument for optimizing the design of new services, in particular the interaction design along the customer journey. It allows harvesting the economic potential of new data-based technologies for service customization. A validation of the practical applicability of our model will been done by field studies with firms offering services in hybrid ecosystems.

The proposed method of linking customisation parameters with value outcomes is only a starting point. Further research should address the following open issues:

- Deriving and validating the customer cost function $f_{\text {CustomerCost }}\left(\vec{C}_{e}\right)$ for prototypical service contexts like B2C, B2B and for different industry sectors.

- Developing instruments to derive the provider cost function $f_{\text {ProviderCost }}(\vec{P})$ (graphs in Fig. 4 ) based on available information within the firm.

- Extending the approach for a population of many customers with different customization expectations.

- Applying the approach to different industries and firms in order to identify prototypical optimization potential by moving towards the Pareto frontier, starting from today's operating point.

- Extending the model with an additional market model, predicting the marked demand as a function of the value creation for the customer. On a market level, moving from $\mathrm{C}$ to $\mathrm{B}$ is expected to decrease the demand and might reduce the total profit (total value capture) of the firm, even if on the level of an individual customer, the value capture is increased.

- Using the model for determining the optimum price $P_{r}$ of a service, offered in a specific market. This might be done by adding price sensitivity functions.

- The model described here is focused on a single walk through the customer journey. How can impacts on value beyond this be incorporated, e.g., additional future revenues due to good customer experience?

\section{ACKNOWLEDGMENT}

The authors would like to thank ZHAW digital for the support of this work.

\section{REFERENCES}

[1] D. Kindström and C. Kowalkowski, "Service innovation in productcentric firms: a multidimensional business model perspective," Journal of Business \& Industrial Marketing, vol. 29, no. 2, pp. 96-111, Jan. 2014, publisher: Emerald Group Publishing Limited.

[2] S. L. Vargo and R. F. Lusch, "From goods to service(s): Divergences and convergences of logics," Industrial Marketing Management, vol. 37, no. 3, pp. 254-259, May 2008.

[3] G. Lay, "Introduction," in Servitization in Industry, G. Lay, Ed. Cham: Springer International Publishing, 2014, pp. 1-20.

[4] H. Gebauer, G.-J. Ren, A. Valtakoski, and J. Reynoso, "Service-driven manufacturing," Journal of Service Management, 2012, publisher: Emerald Group Publishing Limited.

[5] C. Kowalkowski and W. Ulaga, Service strategy in action: A practical guide for growing your B2B service and solution business. Service Strategy Press, 2017.

[6] H. Lightfoot, T. Baines, and P. Smart, "The servitization of manufacturing: A systematic literature review of interdependent trends," International Journal of Operations \& Production Management, vol. 33, no. 11-12, pp. 1408-1434, 2013.

[7] Y. G. Chen, C. M. Hsu, and Z. H. Chen, "The service design strategy of manufacturing service industry," in PICMET 2010 TECHNOLOGY MANAGEMENT FOR GLOBAL ECONOMIC GROWTH, Jul. 2010, pp. 1-6, iSSN: 2159-5100.

[8] J. Ebeling, T. Friedli, E. Fleisch, and H. Gebauer, "Strategies for Developing the Service Business in Manufacturing Companies," in Servitization in Industry, G. Lay, Ed. Cham: Springer International Publishing, 2014, pp. 229-245.

[9] S. L. Vargo, P. P. Maglio, and M. A. Akaka, "On value and value cocreation: A service systems and service logic perspective," European management journal, vol. 26, no. 3, pp. 145-152, 2008, publisher: Elsevier.

[10] S. L. Vargo and R. F. Lusch, "Evolving to a New Dominant Logic for Marketing," Journal of Marketing, vol. 68, no. 1, pp. 1-17, Jan. 2004, publisher: SAGE Publications Inc.

[11] P. P. Maglio and C. Lim, "On the Impact of Autonomous Technologies on Human-centered Service Systems," in The SAGE Handbook of Service-Dominant Logic. 55 City Road: SAGE Publications Ltd, 2018, pp. 689-699. [Online]. Available: http://sk.sagepub.com/reference/thesage-handbook-of-service-dominant-logic/i4682.xml

[12] D. Windsor, "Value Creation Theory: Literature Review and Theory Assessment," in Stakeholder Management, ser. Business and Society 360. Emerald Publishing Limited, Jan. 2017, vol. 1, pp. 75-100. [Online]. Available: https://doi.org/10.1108/S2514-175920170000004

[13] M. P. Joly, J. G. Teixeira, L. Patrício, and D. Sangiorgi, "Leveraging service design as a multidisciplinary approach to service innovation," Journal of Service Management, 2019, publisher: Emerald Publishing Limited.

[14] A. Osterwalder, Y. Pigneur, G. Bernarda, and A. Smith, Value Proposition Design: How to Create Products and Services Customers Want. John Wiley \& Sons, Oct. 2014.

[15] S. E. Sampson and R. B. Chase, "Customer contact in a digital world," Journal of Service Management, vol. 31, no. 6, pp. 1061-1069, Jan. 2020, publisher: Emerald Publishing Limited. [Online]. Available: https://doi.org/10.1108/JOSM-12-2019-0357

[16] C. Mele, T. R. Spena, and S. Peschiera, "Value Creation and Cognitive Technologies: Opportunities and Challenges," Journal of Creating Value, vol. 4, no. 2, pp. 182-195, Nov. 2018, publisher: SAGE Publications India. [Online]. Available: https://doi.org/10.1177/2394964318809152

[17] A. T. Jones, D. Romero, and T. Wuest, "Modeling agents as joint cognitive systems in smart manufacturing systems," Manufacturing Letters, vol. 17, pp. 6-8, Aug. 2018. [Online]. Available: http://www.sciencedirect.com/science/article/pii/S2213846318300440

[18] V. N. Lu, J. Wirtz, W. H. Kunz, S. Paluch, T. Gruber, A. Martins, and P. G. Patterson, "Service robots, customers and service employees: what can we learn from the academic literature and where are the gaps?" Journal of Service Theory and Practice, vol. 30, no. 3, pp. 361-391, Jan. 2020, publisher: Emerald Publishing Limited. [Online]. Available: https://doi.org/10.1108/JSTP-04-2019-0088

[19] A. Schroeder, P. Naik, A. Ziaee Bigdeli, and T. Baines, "Digitally enabled advanced services: a socio-technical perspective on the role of the internet of things (IoT)," International Journal of Operations \& Production Management, vol. 40, no. 7/8, pp. 1243-1268, Jan. 
2020, publisher: Emerald Publishing Limited. [Online]. Available: https://doi.org/10.1108/IJOPM-03-2020-0131

[20] R. Schüritz, K. Farrell, B. W. Wixom, and G. Satzger, "Value CoCreation in Data-Driven Services: Towards a Deeper Understanding of the Joint Sphere," ICIS 2019 Proceedings, Nov. 2019.

[21] D. Mourtzis, S. Fotia, N. Boli, and E. Vlachou, "An approach for the modelling and quantification of PSS customisation," International Journal of Production Research, vol. 56, no. 3, pp. 1137-1153, Feb. 2018, publisher: Taylor \& Francis eprint: https://doi.org/10.1080/00207543.2017.1378956. [Online]. Available: https://doi.org/10.1080/00207543.2017.1378956

[22] K. N. Lemon and P. C. Verhoef, "Understanding Customer Experience Throughout the Customer Journey," Journal of Marketing, vol. 80 , no. 6, pp. 69-96, Nov. 2016, publisher: SAGE Publications Inc. [Online]. Available: https://doi.org/10.1509/jm.15.0420

[23] G. Roels, "Optimal Design of Coproductive Services: Interaction and Work Allocation," Manufacturing \& Service Operations Management, vol. 16, no. 4, pp. 578594, Aug. 2014, publisher: INFORMS. [Online]. Available: https://pubsonline.informs.org/doi/abs/10.1287/msom.2014.0495

[24] U. S. Karmarkar and G. Roels, "An Analytical Framework for Value Co-Production in Services," Service Science, vol. 7, no. 3 pp. 163-180, Aug. 2015, publisher: INFORMS. [Online]. Available: https://pubsonline.informs.org/doi/abs/10.1287/serv.2015.0103

[25] E. Levin, R. Pieraccini, and W. Eckert, "A stochastic model of humanmachine interaction for learning dialog strategies," IEEE Transactions on Speech and Audio Processing, vol. 8, no. 1, pp. 11-23, Jan. 2000 conference Name: IEEE Transactions on Speech and Audio Processing.

[26] A. Polaine, L. Løvlie, and B. Reason, Service Design: From Insight to Inspiration. Rosenfeld Media, Mar. 2013.

[27] A. P. Parasuraman, V. Zeithaml, and L. Berry, "SERVQUAL A Multipleitem Scale for Measuring Consumer Perceptions of Service Quality,' Journal of Retailing, vol. 64, pp. 12-40, Jan. 1988.

[28] A. Golnam, P. Ritala, V. Viswanathan, and A. Wegmann, "Modeling Value Creation and Capture in Service Systems," in Exploring Services Science, ser. Lecture Notes in Business Information Processing, M. Snene, Ed. Berlin, Heidelberg: Springer, 2012, pp. 155-169.

[29] M. B. Lieberman and N. Balasubramanian, "Measuring Value Creation and Its Distribution Among Stakeholders of the Firm," Social Science Research Network, Rochester, NY, SSRN Scholarly Paper ID 2382099 , Jun. 2007. [Online]. Available: https://papers.ssrn.com/abstract=2382099

[30] H. Saarijärvi, P. Kannan, and H. Kuusela, "Value co-creation: theoretical approaches and practical implications," European Business Review, vol. 25, no. 1, pp. 6-19, Jan. 2013, publisher: Emerald Group Publishing Limited. [Online]. Available: https://doi.org/10.1108/09555341311287718

[31] K. Miettinen, "Introduction to Multiobjective Optimization: Noninteractive Approaches," in Multiobjective Optimization: Interactive and Evolutionary Approaches, ser. Lecture Notes in Compute Science, J. Branke, K. Deb, K. Miettinen, and R. Słowiński, Eds. Berlin, Heidelberg: Springer, 2008, pp. 1-26. [Online]. Available: https://doi.org/10.1007/978-3-540-88908-31 